\title{
Os artistas como pesquisadores na virada pedagógica da arte
}

\author{
Tatiana Fernández \\ Universidade de Brasília (UnB) \\ Rosana de Castro \\ Universidade de Brasília (UnB)
}

\begin{abstract}
Resumo
Este artigo apresenta um estudo da história das políticas de formação de artistas e professores de arte no Brasil com o objetivo de entender o contexto em que a ideia de artista pesquisador aparece e como se relaciona com o surgimento da virada pedagógica na arte contemporânea. Ambos os movimentos colocam em questionamento o sentido de uma formação acadêmica nos moldes das ciências e apontam sobre as metodologias de investigação baseadas em arte (IBA). Essas mudanças desenham possibilidades para a prática e ensino da arte que merecem ser observadas em função das potencialidades e desafios da formação desses profissionais na perspectiva do contexto latinoamericano contemporâneo. Propõem-se nessas bases algumas ações concretas a esse respeito na educação superior.
\end{abstract}

Palavras-chave: Artista pesquisador. Virada pedagógica. Investigação baseada em arte. Formação de professores de arte. Educação em artes visuais.

Uma das revoluções no mundo das ideias, diz Arthur Efland (1990), é a profissão de professor de arte no ensino básico porque é a primeira vez que um não artista ensina arte. $\mathrm{Na}$ origem, a partir da Revolução Industrial no século XIX, esses professores eram formados em escolas normais ou escolas de artes e ofícios (MACDONALD, 2004), sob perspectiva que estava mais ligada às ciências da educação do que às artes. Somente na segunda metade do século XX essa formação passou a ser substituída pelo estudo profissional da arte na educação superior. Da mesma forma nesse período começa a formação de professores de arte na educação superior. 
Nesse contexto começa a se construir a ideia do artista como pesquisador a partir das discussões que se cruzam com o ensino da arte entre as décadas de 1960 e 1980 com Elliot Eisner e Tom Barone, que defendem a arte como uma forma de construção de conhecimento, com uma forma própria e diferente de operar. Sobre essas bases se constitui a Pesquisa Baseada em Arte (PBA) (em inglês Arts Based Reasearch, ABR). Na década de 1990 a PBA (ou $A B R$ ) difunde-se no âmbito acadêmico artístico e na primeira década do século XXI se consolida.

Ao mesmo tempo surge o que Claire Bishop chama de virada pedagógica na arte onde os artistas trabalham com interfaces pedagógicas incursionando na pesquisa em educação. Ambos os movimentos, o do artista pesquisador e da virada pedagógica na arte, apresentam oportunidade de reconstrução dos paradigmas da educação, além de ter amplas repercussões sobre a ideia de artista e arte.

Este artigo apresenta um estudo das políticas de formação de artistas e professores de arte no Brasil, para entender o contexto em que a ideia de artista pesquisador e a virada pedagógica da arte desenham mudanças que devem ser observadas em função das potencialidades e desafios da formação desses profissionais na perspectiva do contexto latino-americano contemporâneo. Propõem-se nessas bases algumas ações concretas a esse respeito na educação superior.

\section{A formação de artistas e professores de arte}

No Brasil, logo após a proclamação da república, em 1889, os Decretos no 983 (1890) e no 981 (1890) determinaram que a formação do professor de arte para atuar em sala de aula, do que se denomina atualmente de educação básica, ficaria sob a responsabilidade das escolas normais. Ainda que, pudesse ter ficado sob a responsabilidade da Escola Nacional de Belas Artes, conforme reivindicava o diretor Rodolfo Bernardelli: "seria de imensa vantagem que os iniciadores da lei em nosso país reservassem exclusivamente para os portadores de diplomas da Escola Nacional o direito ao professorado público das artes plásticas em qualquer grau de desenvolvimento" (DAZZI; VALLE, 2010, p. 20). A reivindicação de Bernardelli fundamentava-se sobre a ideia de impulsionar a procura pela formação artística em nível superior e garantir o ensino da arte nas escolas por profissionais qualificados. Entretanto, a proposta de Bernardelli não logrou êxito. Por determinação do Decreto no 981 (1890) o exercício do magistério no primário - primeiro e segundo grau - só poderia ser exercido por egressos da Escola Normal, determinação que impedia os artistas formados pela Escola Nacional de Belas Artes de atuarem em sala de aula.

Em síntese, nesse cenário histórico da primeira república brasileira, a formação da mão de obra para o trabalho industrial ficou a cargo das normalistas, que lecionavam sob a concepção do ensino científico e industrial. E, a formação do artista, em nível superior, 
continuaria sendo ofertada pela Escola Nacional de Belas Artes sob a perspectiva da atuação artística para servir ao governo pela elaboração dos projetos arquitetônicos para os prédios públicos e pelas produções pictórica e estatuária endereçadas aos registros históricos tanto pelos retratos dos políticos quanto das suas ações governamentais.

Alguma mudança naquele cenário ocorreu com a Reforma Benjamin Constant de 1890, a qual proporcionou a oferta de cursos livres em nível superior, antes restrita à jurisdição da sede da corte na cidade do Rio de Janeiro. Tal mudança impulsionou a inauguração das escolas de belas-artes em outros locais do Brasil: (a) Instituto Livre de Belas Artes do Rio Grande do Sul, em 1908, (b) a Escola de Belas Artes de Recife, em 1932; e, (c) a Academia de Belas Artes de São Paulo, 1925, que contou com financiamento particular.

Vale ressaltar que, enquanto a Escola de Belas Artes de Recife, apesar de iniciar atividade no anos 1930, ainda mantinha o ensino no modelo acadêmico e clássico, mesmo com a eclosão da movimentação em torno das ideias modernistas em São Paulo (BARBOSA, 2009); o Instituto Livre de Arte, no sul, inaugurado no início de 1900, pautava-se pela ideia do projeto civilizatório, tinha o mesmo propósito defendido por Araújo de Porto Alegre, ex-diretor da Academia Imperial de Belas Artes (AIBA), que na Reforma Pedreira de 1854 orientou o ensino técnico de artes e ofícios para a promoção do ensino da arte orientado à industrialização no âmbito da AIBA (SQUEFF, 2000). Esses fatos históricos indiciam a sobreposição de modelos, objetivos e práticas pedagógicas que foram se formando em torno da sistematização do ensino superior das artes no Brasil.

Nos anos 1920, junto à movimentação intensa que impactava a tradição artística clássica e o seu ensino na formação do artista, o posicionamento governamental de resistência à criação de universidades começava a enfraquecer frente as investidas dos intelectuais brasileiros, principalmente da área científica. A Academia Brasileira de Ciências $(A B C)$ e a Associação Brasileira de Educação ( $A B E$ ) figuraram como protagonistas de tal movimentação (PAIM, 1982).

Muitos foram os debates travados e liderados principalmente pela Escola Politécnica do Rio de Janeiro, até que o governo Vargas, nos anos 1930, adotasse a criação de universidades como plataforma (PAIM, 1982). No primeiro ano daquele governo, foi promulgado o Decreto no 19851 (1931) determinando que o ensino superior brasileiro obedeceria, preferencialmente, o sistema universitário. Mantendo-se, portanto, a possibilidade da oferta em institutos isolados.

$\mathrm{Na}$ esteira do decreto e da descentralização da oferta da esfera federal para estadual, Anísio Teixeira, então secretário de instrução pública, fundou a Universidade do Distrito Federal (UDF). Fávero (2008) explica que a UDF tinha por missão formar profissionais e técnicos em várias áreas e também para o exercício do magistério em todos os níveis. 
Em São Paulo, um ano antes da fundação da UDF, o governo estadual tinha fundado a Universidade de São Paulo (USP). Tanto a UDF quanto a USP experimentariam mudança de paradigma, o ensino superior ofertados por ambas deixava a tradição de formação de mão de obra pela perspectiva da ciência aplicada. Ao romper com esse legado, essas universidades reivindicavam o espaço universitário, com prioridade, para pensar, debater e propor.

Neste sentido, os anseios da intelectualidade científica e educacional brasileira, representada pela $A B E$ e $A B C$, começou a tornar-se realidade. Contudo, explica Fávero (2008), as políticas educacionais elaboradas pelo Estado Novo organizavam-se de modo regulador e autoritário. O ministro da educação e saúde, Gustavo Capanema, por intermédio do Decreto no 421 (1938) estabeleceu, entre outras obrigações, que nenhum estabelecimento de nível superior fosse aberto no país sem autorização federal. O mesmo decreto também determinava o limite de vagas de acordo com a capacidade das instalações e corpo docente, fato que culminaria nos vestibulares. Além disso, essas determinações resultaram no fechamento de diversos institutos livres, inclusive os endereçados ao ensino superior de arte, e redução da oferta de vagas em escolas de nível superior.

Outro ponto defendido por Capanema situava as universidades como, nada mais, que o conglomerado de escolas e institutos já existentes. Sobre isso, em carta dirigida a Vargas, o ministro afirma que a ideia de universidade ficava só no papel, "sem qualquer elo que as unisse, as faculdades permaneciam... independentes e continuavam a ser o que até então haviam sido, isto é, institutos isolados de ensino superior" (SCHWARTZMAN, 1985, p. 368).

A UDF foi frontalmente atingida pelas investidas de Capanema no terreno do ensino superior. A proposta dele para conceber a Universidade do Brasil e para construir um campus específico, promoveu o encerramento das atividades da universidade concebida por Anísio Teixeira com a publicação do Decreto oㅡ 1063 (1939). O desacordo ideológico e político entre Capanema e Teixeira tinha como cerne a vinculação do primeiro com o pacto entre o governo Vargas e a igreja católica, enquanto a UDF referenciava-se nos pressupostos do modernismo e pragmatismo americano.

No que diz respeito ao curso superior de arte, a Universidade do Brasil absorveu a Escola de Belas Artes, enquanto a UDF criou um Instituto de Artes. A distinção ideológica e política de entre ambas não pode deixar de ser considerada. Enquanto a Escola de Belas Artes estruturou-se sobre o modelo humanístico, o Instituto de Artes da UDF adotou o modelo modernista que problematizava as relações entre a indústria e a arte. O Instituto de Arte da UDF tinha influência do construtivismo, talvez, não por acaso, o instituto tenha sido fechado e as suas atividades absorvidas pela Escola de Belas Artes.

Sobre essa absorção, Capanema defendia-se citando o projeto aprovado no concurso para o projeto do Ministério da Educação. A edificação, que recebeu o seu nome, foi erigida por traços modernistas do projeto vencedor, apresentado por uma equipe de arquitetos entre 
os quais, Lúcio Costa e Oscar Niemeyer. Além disso, em carta escrita a Vargas, na qual analisa os resultados da educação brasileira, Capanema ressalta, "se o governo não pode, por sua natureza, adotar esta ou aquela concepção estética, assiste-lhe, contudo, o dever de não ficar indiferente à revisão do gosto!" (SCHWARTZMAN, 1983, p. 374). O discurso de Capanema é nitidamente semelhante àquele defendido pelo primeiro governo republicano, reduzindo a arte à questão do gosto. Para ambos os governos Vargas e da primeira república, o debate intelectual das vanguardas modernistas deveria ser mantido longe das instituições de ensino superior.

A disputa em torno da superação dos cânones clássicos (das academias de belas-artes) por métodos abertos à criação e à expressão individual do artista (DAICHENDT, 2009; WICK, 1989), pode ser observado em diferentes escolas europeias nas primeiras décadas do século XX. Stankiewicz (2009) ressalta que a National Society of Arts Masters defendia a vertente clássica mantendo a tradição dos cânones nas academias inglesas de belas-artes. Por outro lado, James Daichendt (2009) sinaliza para as modificações ocorridas no ensino do desenho na Manchester School of Design, onde o método da cópia literal foi substituído pelo método centrado na originalidade e na criação pela prática artística em desenho de botânica, das figuras humanas e da anatomia animal.

Ainda em relação às mudanças na formação dos artistas, Rainer Wick (1989) explica que a experiência a Bauhaus, na Alemanha, fundiu os modelos de produção industrial e artesanal em seus cursos, superou o antagonismo entre a "arte elevada (formalizada pelas academias)" e a produção artesanal "depreciativamente qualificada como inferior (pela vertente clássica do ensino da Arte)" (p. 4). Nessa direção, G. Carlo Argan (1988) afirma que a experiência da Bauhaus, ainda que orientada pelo racionalismo, garantiu espaço às "atividades [de formação] dirigidas a estimular a imaginação" dos artistas (p. 272). Em princípio, tanto a escola alemã (WICK, 1989) quanto a escola inglesa (DAICHENDT, 2009) confrontaram a noção de natureza como fonte para a cópia das formas pelo argumento de que prática imitativa limitava a criação (ARGAN, 1988; WICK, 1989), aspecto combatido na formação artística modernista.

Ao avançar no tempo, constata-se que, em relação à formação de professores de Artes Plásticas, a Escolinha de Artes do Brasil (EAB) ofertava, desde 1961, o Curso Intensivo de Arte na Educação (FRANGE, 2006). A base dessa formação eram as ideias de Herbert Read (2001) originadas nos estudos sobre a expressão artística da criança, realizados pelo autor, em 1948, na Inglaterra marcada pelo esforço regenerador do contexto sociocultural do período pós-guerra. Read (2001) anunciou que a Arte era a base para Educação. E os objetivos dessa última seriam propiciar o crescimento do que é individual em cada ser humano e auxiliar na aliança harmônica entre a individualidade e a unidade orgânica do grupo social. 
Com objetivo distinto ao curso de formação da Escolinha de Arte do Brasil, a Licenciatura em Desenho ofertada pelas Faculdades de Ciências, Letras e Filosofia (FCLF), no início dos anos 1960, formava professores para lecionar desenho geométrico nas escolas de Ensino Médio (MACHADO; FLORES, 2013). Essa licenciatura tinha cariz matemático e científico herdado da longa trajetória do ensino do desenho iniciada para atender à demanda político-econômica por capacitação de mão-de-obra industrial nos anos 1800. Apesar das inúmeras mudanças ocorridas no sistema educacional brasileiro, a ênfase das disciplinas matemáticas na estrutura curricular da formação para a arte permaneceu nos cursos de professores de desenho até a década de 1960.

Em 1969, a Licenciatura em Desenho cedeu lugar à Licenciatura em Desenho e Artes Plásticas, em uma tentativa de aproximação da concepção de Arte como expressão difundida pelas Escolinhas de Artes do Brasil (MACHADO; FLORES, 2013). Tal reforma não logrou êxito, as disciplinas matemáticas continuaram em maior número resultando em um currículo aquém da proposta inicial daquela reforma.

Esse viés técnico-científico seguiu em grande parte das habilitações em Desenho e Artes Plásticas ofertadas pelos cursos de arte no Brasil. Vale ressaltar que a Escolinha de Arte era uma instituição de ensino não formal, característica que contribuiria para enfraquecer a possibilidade de adoção da proposta de Read (2001) no âmbito dos cursos superiores sitiadas pelo regime militar iniciado em 1964. Sob tal circunstância, artistas e educadores organizados no Movimento Escolinhas de Artes (MEA) atuaram contestando a formação universitária tecnicista do educador artístico e reivindicando reformas na formação dos professores de arte para a educação básica (DUARTE, 2011).

Essas contestações encontrariam respaldo somente na abertura política dos primeiros anos da década de 1980, quando a formação de professores foi amplamente debatida no contexto dos cursos de Pedagogia. Os debates desencadearam a adesão de sindicatos e associações de ensino e pesquisa ao movimento de reforma curricular dirigida à formação dos pedagogos. Esse movimento reverberou para as demais licenciaturas e provocou a adesão de outras áreas do conhecimento à discussão sobre a formação de professores (BRZEZINSKI, 1992). Nessa direção, a Federação de Arte Educadores do Brasil (FAEB) e a Associação Nacional de Pesquisa em Artes Plásticas (ANPAP) atuaram em conjunto com as associações de Música e de Teatro, na liderança das reformas na Licenciatura em Educação Artística (BARBOSA, 2003).

Tais mobilizações contribuíram para conquistas importantes, entre as quais, a criação das Licenciaturas em Artes Plásticas. O cerne dessa criação foi a inclusão da Arte como disciplina obrigatória no currículo da Educação Básica (BRASIL, 1996, 2005). A Licenciatura em Artes Plásticas, pela primeira vez no ensino da arte para educação básica, eliminou o caráter técnico-científico da formação de professores, substituindo-o pela ideia moderna de 
produção. Essa concepção de ensino estava vinculada à estética e à ideia da plasticidade dos materiais artísticos, a qual se centrava na exploração desses materiais sem os rígidos padrões canônicos das Belas-Artes (DIAS, 2011).

$\mathrm{Na}$ esteira das reformas do ensino superior concretizadas pelas diretrizes e base da educação (Brasil, 1996), especialistas, pesquisadores e docentes das Instituições de Ensino Superior (IES) foram envolvidos na elaboração das Diretrizes Curriculares Nacionais para o Curso de Graduação em Artes Visuais (DCN/AV) nos anos 2000. A publicação das DCN/AV (BRASIL, 2009) implicou em mais uma reforma, que resultou na criação da Licenciatura em Artes Visuais.

Na maioria dos países da América Latina e Caribe se adota a obrigatoriedade do ensino das artes na metade da década de 1990, (muitas delas entre 1996 e 1998) geralmente com uma abordagem cognitivista para contribuir com a capacidade criativa e inovadora na ciência e na tecnologia tanto quanto nas áreas sociais e culturais. Estas mudanças estão ligadas às reformas educativas promovidas naquele momento pelo Banco Interamericano de Desenvolvimento, BID, e pelo Banco Mundial no começo da década, na região, com o objetivo de favorecer a economia de capital e informacional, que são os interesses do mercado (SILVA; AZEVEDO, 2012). As propostas abordam a arte na educação para o desenvolvimento da capacidade criadora que inclui uma série de habilidades, destrezas e atitudes necessárias para o mundo do trabalho no contexto da informatização da sociedade.

Estas reformas criaram maior demanda de professores especializados em arte, mas até finalizar o século XX a formação era fundamentalmente formação específica, poucas foram as instituições de ensino superior que formaram professores e artistas juntos até os dias de hoje. Isso impediu que os professores de arte conheçam melhor os processos criativos nas artes e que os artistas conheçam algo de educação.

Sob a perspectiva de Tracey Hunger-Doginer (2013), na situação atual, os professores de Arte se veem isolados dentro das escolas, incumbidos da defesa da relevância da sua área de formação e atuação, "part of the nature of the [...] art educators is to advocate for the invaluable place of art in the learning process" (HUNGER-DOGINER, 2013, p. 173). Amanda Alisson (2013) apresenta proposta de formação, na qual enfatiza o que denominou de duplo papel do professor de Arte, como artista e como docente, marcados pela necessidade de formação nas duas áreas (Arte e Educação). Segundo a autora, a estratégia adequada para qualificar a atuação do professor de Arte em serviço é favorecer espaço para a prática artística como exercício de criação e produção, com o objetivo de compensar a ausência de tal prática na formação inicial ou pelo pouco tempo dedicado ao ateliê como consequência da demanda de horas de atuação em sala de aula.

Ainda sobre a formação de professores de Arte em serviço, James Hall (2010), em investigação sobre a atuação do artista-professor nas escolas inglesas, buscou pistas entre 
os participantes do Artist Teacher Scheme (ATM) e do Master in Art Education (MAE) da Roehampton University sobre como ocorreria a articulação entre a prática artística e a prática pedagógica em suas atuações. O autor revela que os participantes daqueles cursos de formação continuada sinalizaram para a dificuldade em promover tal articulação; também que não houve consenso entre os artistas-professores sobre a necessidade real de obter conhecimentos pedagógicos para atuar no ensino da Arte em sala de aula.

Sob a perspectiva de Hall (2010), entre os problemas encontrados, está a dificuldade para a manutenção em sala de aula da postura crítica do artista, comum no exercício das suas produções. O autor explica que, pela perspectiva dos artistas-professores, há o constrangimento da atuação crítica pelas regras e normas escolares. Essas últimas, segundo o relato dos participantes da pesquisa ao autor, tendem a demandar a adequação dos conteúdos aos temas e às faixas etárias, entre outros requisitos do planejamento de ensino; tais adequações iriam de encontro à maneira como artista foi formado para criticar, refletir e produzir sobre as questões da realidade.

De acordo com Paul Bolin e Kaela Hoskings (2013), é importante evidenciar que o professor de Arte atua com referência em pontos de vista particulares, quer tenha consciência, ou não, sobre essa maneira de atuar. Segundo o autor, tal atuação resulta da autonomia daquele professor para as escolhas dos conteúdos, em maior grau, frente aos professores das demais disciplinas. Bolin (2013) assegura que ter autonomia na seleção dos conteúdos (principalmente, imagens) outorga ao professor de Arte a liberdade para definir qual representação da realidade será apresentada aos estudantes.

Bolin e Hoskings (2013) explica que tal prerrogativa requer do arte-educador reflexão acerca do seu posicionamento em relação ao ensino, aos alunos e à sociedade para depois engajar-se na atuação em sala de aula. Nessa direção, ressalta-se que Jeff Adams (2007) defende a adoção das pedagogias críticas ${ }^{1}$ por considerar que tais pedagogias podem favorecer a visão crítica característica da formação em Arte, ao tempo em que dispõe o repertório didático-pedagógico necessário para o professor atuar em sala de aula de maneira a envolver os estudantes em ações relacionadas às questões socioculturais prementes ao meio, no qual estão imersos.

\section{0 artista pesquisador e o ensino superior}

A história da formação de artistas e professores de arte no Brasil revela um padrão na história dos países que investiram na industrialização, como é o caso da Argentina, Colômbia,

\footnotetext{
1 Sob a perspectiva de Giroux (1999), a pedagogia crítica forma o educador com argumentos teóricos e evidências empíricas que lhes permitam perceber que os espaços escolares funcionam como agências de reprodução social, econômica e cultural. As escolas são instrumentos potenciais para a reprodução das relações de produção e ideologias legitimadoras do capitalismo na vida cotidiana.
} 
México ou Chile. Nas últimas décadas a formação artística cresceu em quantidade e qualidade nestes países (DIAS et al., 2017) de forma que é cada vez maior a participação de artistas e professores de arte no debate acadêmico, com contribuições importantes. Nesse cenário a ideia de artista pesquisador encontrou solo fértil no mundo acadêmico.

Mas, embora a ideia de que o artista é pesquisador no sentido em que constrói conhecimento para a sua comunidade ou sociedade, é geralmente aceita na sociedade, o que não é geralmente aceito é o valor que esse conhecimento tem para a vida prática frente ao conhecimento da ciência. Segundo essa perspectiva o conhecimento da arte se centra no produto da obra de arte e a pesquisa do artista se limita à busca da sua autoexpressão. Para Graeme Sullivan (2010) isso significa que os artistas na educação superior pesquisam sobre sua identidade artística antes que sobre o que interessa ao mundo científico ou social. $O$ artista faz uma busca metafísica sobre a sua subjetividade: busca encontrar a si mesmo numa investigação endógena de seu "estilo" ou "técnica" que exprima o que ele tem "para dizer". Nesse sentido não podem se formar artistas, mas selecioná-los nas universidades (Universidad Nacional Colombia, 2012).

Mas a educação superior visa formar profissionais, não os selecionar. Isso é complexo para a formação do artista porque no caso dos países da América Latina e Caribe a arte não se reconhece como profissão. Estudar arte na universidade, como uma profissão, diz Luis Camnitzer (Universidad Nacional Colombia, 2012) é uma fraude porque se vende como um meio de se produzir economia e não é o que acontece no continente. De fato, o estudo da arte no nível superior conduz à aplicação da arte em outras áreas de conhecimento ou de maneira interdisciplinar. São poucos os se tornam "artistas profissionais": os que fazem parte do sistema de produção e circulação internacional. E nesse caso é possível ser profissional da arte sem passar pela formação superior. É uma carreira que não pode garantir o nível do seu profissional. Ainda mais, o artista pode ser autodidata ou estudar outra carreira para articular sua obra. Antes que uma profissão é uma forma de viver.

Mesmo assim no século XXI a demanda e oferta de cursos superiores de arte se multiplicou, como também a de formação de professores de arte. A publicidade das instituições para formação artística no Brasil, Chile ou Argentina revela que as faculdades particulares estão oferecendo uma formação artística com um perfil ligado à "economia criativa"² na produção cultural, tecnológica e industrial.

$\mathrm{O}$ artista pesquisador se insere nesse contexto de crescimento da participação da arte no ensino e pesquisa na academia, mas também da profissionalização dos modos de produção e circulação da arte. Isso evidentemente, move o que já estava acomodado:

${ }^{2}$ Economia criativa é o valor agregado que se dá a expressividade e inovação como valores de mercado (HOWKINS, 2012). 
A exigência de grau de Doutor, por exemplo, para que um artista (mesmo que com ampla experiência) possa oferecer um curso de pós-graduação, indica claramente um conflito de legitimações, onde o aparato universitário não abre mão de abrigar primeiramente aqueles reconhecidos pelo seu próprio processo de formação/formatação - é clara a resistência e a autoproteção sem as quais, enfim, a academia veria dissolver-se a constelação de valores científico - humanistas e seu pensamento da arte em termos não artísticos que ainda a estruturam. (BASBAUM, 2016).

Como observa Ricardo Basbaum, para que a arte entre na educação superior seu estudo deve se estruturar em termos não artísticos. Ocorre que no ensino básico a ênfase sobre as competências cognitivas (nas reformas cognitivistas e cientificistas que o BID e BM promoveram na América Latina e Caribe) também se estrutura em termos não artísticos. As metodologias de ensino das artes nessas perspectivas são científicas. Em outras palavras se aprende arte com os métodos das ciências. Nessa situação as artes são exiladas da sua terra.

Mas o artista observa que, na medida que se ampliam os estudos de graduação e pósgraduação em artes, os artistas estão cada vez mais ligados a atividades acadêmicas em universidades. Para ele, isso abre a possibilidade de trazer um "fôlego" (2016, p. 193) para a academia. Quer dizer, a arte pode trazer um espaço de respiração às ciências. No entanto, não passa despercebido por ele que o espaço acadêmico é muito diferente daquele das instituições da arte que demanda aos artistas, outros conhecimentos e ações. Mas, ele adverte, "não há como escapar desta máxima: dentro da universidade, o trabalho de arte se transforma em pesquisa e o artista em pesquisador" (2016, p. 194).

$\mathrm{Na}$ visão dele, nesse contexto há possibilidade de que haja uma contaminação de fazeres-saberes das ações de arte contemporânea na academia que permita ampliar os critérios com os quais legitimamos a formação do artista e no caso também do professor de arte. De toda forma, nem Basbaum, nem Camnitzer ou Graeme Sullivan pensam que a investigação artística possa se realizar fora dos seus particulares modos de operar na construção do conhecimento.

Meu argumento é que para apreciar como as artes visuais contribuem à compreensão humana, é necessário localizar a investigação artística dentro das teorias e práticas do fazer artístico. É deste lugar central de prática criativa que outras formas de investigação emergem, como a análise crítica e filosófica, comentário histórico e cultural e experiência educacional. (SULLIVAN, 2010, p. 97).

Para Sullivan $(2002,2010)$ o saber visual se forma de maneira complexa e dinâmica, entre o conhecido e o desconhecido, trançando relações entre conhecimentos e experiências, assim o artista é um investigador que procura o entendimento através de um processo de aprendizagem em diálogo com a situação, o espectador e o artefato. Nessa visão, a investigação artística é um espaço criativo e educativo onde o sentido se tece no processo e onde há uma continuidade e contiguidade entre teoria, prática e poética. 
Sullivan é um dos mais destacados teóricos da prática da arte como um processo de pesquisa e do artista como um pesquisador. Ele procura os pontos de convergência e divergência entre as metodologias da arte e da ciência e observa que, se por um lado as práticas artísticas integram as diversas tradições científicas, por outro vão além delas e apresentam formas que não se encontram na experiência científica. Na tradição positivista, observa ele (2010), o caminho das probabilidades é linear, busca-se uma resposta. $\mathrm{Na}$ tradição interpretativa o caminho do que é plausível é envolvente para entender as diversas perspectivas. Na IBA o caminho se cria na possibilidade de forma que os caminhos são diferentes e complementares, exploram em toda direção.

Essa figura nos dá uma ideia mais cabal de como ocorre a pesquisa na arte: se criam caminhos onde não os havia. Uma das diferenças fundamentais das IBA é então pesquisar sobre o que ainda não existe, na criação de mundos possíveis. A imaginação e a criação são a base de toda IBA e elas conduzem a formas de investigação que a ciência não tem.

No começo do século XX surge, no âmbito da pesquisa em educação a metodologia de investigação da A/r/tografia, ou metodologia da "grafia" do sujeito artista/pesquisador/professor (DIAS; IRWIN, 2013) que explora a IBA no âmbito específico da educação em artes visuais. A metodologia a/r/tográfica que é hoje muito usada no âmbito da educação, evidencia as possibilidades que a IBA tem para a ciências.

Os artistas contemporâneos trabalham cada vez mais com projetos escritos, seja para obter recursos ou para executá-los. Os projetos de artista são apresentados como processos de investigação. A ênfase sobre o processo antes que o produto, ou uma obra sem produto na arte já procede dos Situacionistas, mas difunde na pós-modernidade. Nesse âmbito se propõem ações e intervenções em que se registra o processo de construção. Ações desse tipo foram realizadas a partir de residências artísticas, ou de projetos sociais, entre outros.

\section{A virada pedagógica na arte}

A virada pedagógica da arte está relacionada de diversas maneiras a ideia do artista como pesquisador e seu papel na transformação social. Trata-se de um movimento que se articula entre a autonomia e a heteronímia da arte: são artistas que enfatizam sobre o valor social da arte e o valor estético da educação. O que interessa a eles são as rupturas na ordem das coisas que conservam o discurso moderno da arte que cria dicotomias entre belo ou útil, sujeito ou objeto, teoria ou prática, corpo ou mente, forma ou substância.

A virada pedagógica na arte também é entendida no âmbito da curadoria de arte e dos programas museais (O'NIELL; WILSON, 2010). Nessa linha as instituições exigem (para alguns impõem) uma contraparte social da obra do artista na exposição. Estratégias de mediação e projetos educacionais respondem a uma necessidade de reportar uma grande 
afluência de públicos aos museus para justificar os financiamentos das agencias culturais. Isso se faz evidente nos programas educativos que se amarram às grandes exposições.

A virada pedagógica na arte e na curadoria tem raízes semelhantes, mas são diferentes os caminhos que tomam e os eventos que provocam. Surgem da crescente participação do público na obra de arte que procede da arte conceitual e da performance na década de 1970 . Um caso é o artista Joseph Beuys que enfatizava o lugar da aprendizagem como o lugar da experiência da arte.

Ensinar é minha maior obra de arte. O resto é desperdício de produto, uma demonstração. Se você quer se expressar você deve apresentar algo tangível. Mas depois de um tempo isto só tem a função de documento histórico. Os objetos não são mais importantes. Eu quero chegar à origem da matéria, ao pensamento que está atrás dele. (BEUYS apud KUONI, 1993, p. 85).

Isso aponta a uma ênfase sobre a arte e sua localização, antecipando a noção de site specific, que pensa a obra em função específica do contexto e situação em que atua. Em 1972 ele realizou duas ações-cátedra na Tate e na Whitechapel Gallery em que conversava com o público durante horas. No mesmo ano realizou o Escritório para uma Democracia Direta $^{3}$, na Documenta 5, onde se envolveu no debate com o público sobre reforma eleitoral. Os quadros-negros que resultaram destas ações-cátedra se acumularam e formaram posteriores instalações da memória do intercambio intelectual. Em 1977, para a Documenta 6. Beuys realizou 100 dias da Universidade Internacional Livre $^{4}$, onde se abriram treze workshops para o público.

Claire Bishop identifica Beuys como o precursor de uma arte socialmente engajada que se cria na interseção entre arte, política e educação (2012, p. 244), embora ele dividisse conceitualmente seu trabalho como escultor e como pedagogo, pois o discurso ainda não se entendia como um evento artístico. Hoje, ela observa, "podemos reconhecer não só o discurso, mas também o ensino como um meio artístico" (BISHOP, 2012, p. 245).

O grupo Fluxus também antecipou o interesse pela pedagogia. Hannah Higgins (2002) lembra que o grupo Fluxus investigava intensamente sobre os processos cognitivos e sobre os artefatos pedagógicos, como Robert Filliou e Benjamin Patterson, ou sobre as práticas nas aulas, como John Cage e lan Baxter, no final dos anos 60. Para o grupo Fluxus o livro do filósofo da educação John Dewey, Arte como experiência, de 1934, revela Higgins, era a sua orientação política.

Depois, o interesse pela educação entre os artistas se propaga na década de $1990 \mathrm{com}$ as discussões sobre o currículo das escolas de arte, como aquele que ocorreu na Goldsmith

\footnotetext{
${ }^{3}$ Boureau for Direct Democracy.

4100 days of the International Free University.
} 
University de Londres, onde estudaram os Jovens Artistas Britânicos ${ }^{5}$ (MADOFF, 2009). No final da década, Dominique González-Foerster, Pierre Huyghe e Philippe Parreno formaram a Escola Temporária com uma série de workshops em diversas escolas e universidades na Europa que criavam situações de aprendizagem em lugares não usualmente usados como um lago congelado ou na cima de uma montanha (VIDOKLE, Anton, NOTES FOR AN ART SCHOOL, 2006).

Assim se fundaram universidades ou escolas como a Universidade Livre de Copenhagen $^{6}$ (CFU) dos artistas dinamarqueses Henriette Heise e Jakob Jakobsen, em 2001 que realizavam investigações em organização feminista, arte e economia, subjetividade escapista, ativismo de televisão/mídia e história da arte. A partir de 2004 surgiram a Universidade Livre de Los Angeles ${ }^{7}$, a Universidade da Abertura em Londres ${ }^{8}$, a Universidade Livre de Manoa ${ }^{9}$, a Universidade Informal de Grundung ${ }^{10}$, a Universidade Tangente ${ }^{11}$, a Academia Momentânea ${ }^{12}$, a Escola Pan-Americana da Intranquilidade ${ }^{13}$ de Pablo Helguera, a Escola Cátedra Arte de Conduta de Tania Bruguera, entre outras. Estas escolas ou universidades têm livre acesso, as relações são horizontais, as abordagens são experimentais e multidisciplinares, usam redes colaborativas, recusam normatizações e atuam de maneira subversiva e criativa (PODESVA, 2007).

Para Bishop (2012) a tendência dos projetos ${ }^{14}$ pedagógicos encontrou força em 2006 quando o artista-curador Anton Vidokle criou a Escola Noturna em Berlim em substituição à Manifesta 6 que foi cancelada por problemas políticos no Chipre. Hoje é a escola unitednationsplaza que dá continuidade à experiência. Esse ano Irit Rogoff iniciou o projeto Academie com outros artistas e colaboradores para pensar o museu como um espaço de educação: "Nascida da crença de que as instituições que habitamos potencialmente podem ser mais do que são, estas questões indagam como o museu, a universidade, a escola de arte, podem ultrapassar suas funções correntes" (ROGOFF, 2008). Existem também outros artistas que trabalham com interfaces pedagógicas na sua obra sem necessariamente criar escolas ou universidades, como Tim Rollins, Paul Althamer ou Thomas Hirschhorn.

\footnotetext{
${ }^{5}$ Young British Artists.

${ }^{6}$ Copenhagen Free University.

${ }^{7}$ Free University of Los Angeles.

8 University of Openess.

${ }^{9}$ Manoa Free University.

10 Informelle Universität in Gründung.

${ }_{11}$ L' Universite Tangente.

12 Momentary Academy.

${ }^{13}$ School of Panamerican Unrest.

${ }^{14}$ Os projetos na arte contemporânea são um formato que permite procurar e se identificar com o trabalho colaborativo, que tem uma duração, que é situado, que tem um caráter transformador ou construtivo e que envolve uma ou várias comunidades.
} 
Embora essas experiências educacionais na arte não entraram na educação formal, para Nadine Kali (2012) a virada pedagógica na arte está relacionada a luta que surge na década de 1990 contra o sistema de mercado neoliberal que institucionaliza a educação na chamada "economia do conhecimento" ou e "economia da aprendizagem", que é a ideia de aprender para viver ou aprender constantemente para servir ao mercado. Trata-se de uma visão economista da educação (HODGINS, 2000). A autora observa que o sistema pósfordista de mercado exige mais que conhecimento profissional: busca a criatividade como uma competência para o trabalho e a disposição ao trabalho colaborativo, mas, paradoxalmente para servir ao sistema do mercado, isto é, dos mais poderosos, em detrimento dos interesses comunitários ou pessoais. A criatividade a construção colaborativa, pensa ela, deve se basear no dissenso e não no consenso "criando formas que alimentem interações democráticas, não somente maneiras engenhosas para atingir determinados objetivos "(KALIN, 2018, p. 102). No espaço da arte a criatividade e a colaboração são formas dissidência e resistência antes que de consenso ou normatividade.

Para Kalin (2012) os artistas da virada pedagógica não somente colocam a pedagogia como um encontro visual, mas também abrem a possibilidade, por meio da investigação na arte, de transformar a educação. Evidentemente estes projetos não se encontram com as dificuldades ou as condições que vivem os espaços educativos públicos ou privados. E por outra parte, como adverte Pablo Helguera (2011), os artistas que trabalham com interfaces pedagógicas devem aprender sobre teorias da educação e conhecer as situações em que se encontram os espaços de ação educativa. De toda forma, ainda com essas diferenças, pensa Kalin, esses artistas se encontram em posição de explorar possibilidades que os gestores e professores dos sistemas da educação não podem, ignoram ou recusam.

Esse movimento na arte deve ter implicações na formação de artistas e professores de arte, que nessa perspectiva diluem as fronteiras alçadas, ou muros levantados entre as profissões de artista e de professor de arte.

\section{Derrubando muros, construindo mundos}

Nesse panorama podemos observar que há uma história de incompatibilidade e estranhamento entre artistas e professores de arte devido às políticas da sua formação que hoje podem confluir a partir da concepção do artista como pesquisador e da virada pedagógica na arte. Inclusive é possível afirmar que a formação do artista hoje é incompleta sem as discussões da sua educação e que a formação do professor de arte é incompleta sem as discussões da arte. No Brasil e na América Latina a formação conjunta de artistas e professores de arte é rara, mas quando existe tende a fazer aparecer as marcas políticas da sua história e a sua dependência das ideias modernas de Ocidente. O encontro dos estudantes de bacharelado e licenciatura (licenciatura e profesorado em alguns países latino- 
americanos) enfrenta questionamentos sobre o papel do artista e da arte na sociedade que interessa tanto a professores com artistas.

Como bem nota Cayo Honorato (2014), há duas subjetividades que se formam nesse processo, os artistas professores e os professores artistas. Estes últimos ligados às explorações da metodologia de pesquisa a/r/tográfica (DIAS; IRWIN, 2013). Em qualquer um dos casos os questionamentos têm implicações políticas e metodológicas relevantes. Por uma parte porque criam uma ruptura com o papel do artista e da arte na sociedade e focam sobre formas socialmente engajadas de experiência estética. Por outra parte porque se fortalecem as formas de operar das artes, que são metodologias na construção do conhecimento coletivo e com eles surgem possibilidades de transformação social.

Em base a estes estudos propomos ações que permitam estudar adequações curriculares e metodológicas na formação de artistas e professores de arte que possam derrubar os muros que separaram historicamente estes profissionais e construir novos mundos. Existem diversas possibilidades e dependem dos contextos e situações, mas de maneira geral podemos destacar três ações concretas que abrem espaços de resistência em diversos contextos.

Em primeiro lugar podemos destacar a vasta exploração e sistematização das formas da IBA em todos os níveis de pesquisa. Para isso é necessário desenvolver habilidades e destrezas na elaboração e execução de projetos artísticos e artístico educativos. Trata-se, pois, de dar ênfase ao estudo das formas de operar das artes, tanto do ponto de vista do artista como do participante da obra. A IBA por outra parte promove incursões em caminhos de subversão e resistência que se aproximam das necessidades de emancipação e descolonização cultural do continente americano. O giro em direção ao que arte pode fazer, ao invés do que a arte significa é um giro descolonizador.

Em segundo lugar estas mudanças apontam formas de aprendizagem inter, multi e transdisciplinar integrando diversas competências ao redor de projetos de trabalho onde a autoformação possa tomar o lugar do modelo de transmissão. Se o artista é um pesquisador ele deve desenvolver esse tipo de competências. Para formar artistas pesquisadores e professores de arte/pesquisadores é necessária uma ênfase sobre o seu valor para a construção de espaços de vida.

E em terceiro lugar apontam uma abertura curricular radical aos estudos visuais e estudos culturais que a formação de artistas e professores de arte não tiveram até o fim da modernidade. Para América Latina isso adquire um significado particular porque se associa aos processos de descolonização. Estudar a arte requer também um estudo das formas de olhar sem os quais os conhecimentos artísticos perdem densidade e sentido. A pedagogia crítica aqui adquire um papel relevante na problematização das formas de olhar. 
Nesse movimento a arte vai além dela, em direção a formas de construção democrática do conhecimento. Por esse motivo, na formação desses profissionais, é importante apontar às problemáticas que envolvem discussões feministas, queer, de descolonização do pensamento, dos estudos culturais, da cultura visual, do pós-humano e das mídias e tecnologias entre outras, que são discussões políticas. Inclusive a IBA tem um alcance político: coloca em questionamento a validade da objetividade na ciência e a sua visão dicotômica do mundo. Esse é um levantamento frontal à tradição da ciência moderna ocidental e suas recentes políticas homogeneizadoras e de rendimento de contas que renascem na década de 1980. O campo da educação é onde mais tem se aplicado a cultura do rendimento de contas e de avaliações e a figura do artista como pesquisador e a virada pedagógica na arte minam esses pressupostos criando um espaço real de resistência em meio às mudanças globais em direção aos projetos neoliberais. Nesse sentido este é um momento interessante para o artista pesquisador e professor de arte. Mas é também um momento de reformular os alcances da educação em artes visuais na América Latina.

\section{Referências}

ADAMS, Jeff. Artists becoming teachers: Expressions of identity transformation in virtual forum. The Journal of Art \& Design Education, v. 26, 2007, P. 264-27.

ALLISON, Amanda. No teacher behind: Professional development that really matters an age of accountbility. Art Education Policy Review, 2013, p. 114-178

ARGAN, G. Carlo. A arte moderna. São Paulo: Cia das Letras, 1988.

BARBOSA, V. Escola de Belas Artes de Pernambuco. Pesquisa Escolar Online, Fundação Joaquim Nabuco, Recife, 2009. Disponível em: http://basilio.fundaj.gov.br/pesquisaescolar/.

BASBAUM, Ricardo. O artista pesquisador. In: Manual do artista etc. Rio de Janeiro: Beco do azougue. p. 193-201, 2013

BISHOP, Claire. Artificial Hells: participatory art and the politics of spectatorship. (ebook) London: Verso, 2012.

BOLIN, Paul; HOSKINGS, Kaela G. We do what we believe: A contemporary and historical look at personal and programmatic purposes of art education. The Journal of the Texas Art Education Association, v. 1, 2013, p. 62-68.

BRASIL. Decreto № 19.851, de 11 de abril de 1931. Disponível em: https://www2.camara.leg.br/legin/fed/decret/1930-1939/decreto-19851-11-abril-1931-505837republicacao-139891-pe.html.

BRASIL. Decreto-lei no 1.063, de 20 de janeiro de 1939. Disponível em: https://www2.camara.leg.br/legin/fed/declei/1930-1939/decreto-lei-1063-20-janeiro-1939-349215publicacaooriginal-1-pe.html.

BRASIL. Decreto-Lei no 421, de 11 de maio de 1938. Disponível em: https://www2.camara.leg.br/legin/fed/declei/1930-1939/decreto-lei-421-11-maio-1938-350759publicacaooriginal-1-pe.html.

BRASIL. Lei de Diretrizes de Bases da Educação, 1996.

BRASIL. Parecer do Conselho Nacional de Educação no 02/2005. 
BRASIL. Publicação Original [Coleção de Leis do Brasil de 31/12/1890 - vol. 011] (p. 3533, col. 1). Decreto $n^{\circ} 983$ de 08/11/1890.

BRASIL. Publicação Original [Coleção de Leis do Brasil de 31/12/1890 - vol. 011] (p. 3474, col. 1). Decreto $n^{\circ} 981$ de 08/11/1890.

BRZEZINSKI, Iria. Trajetória do movimento para as reformulações curriculares dos cursos de formação de profissionais da educação: do comitê (1980) à anfope (1992). Em Aberto, Brasília, v. 12, n. 54, abr./jun. 1992.

CAMNTZER, Luis. The Detweeting of Academia. e-flux Jounal, n. 62, Feb. 2015. Disponível em: http://www.e-flux.com/journal/the-detweeting-of-academia/. Acesso em: 12 fev. 2015.

DAICHENDT, James. George Wallis: The original artist-teacher. Teaching Arts Journal, v. 7, n. 4, 2009, p. 219-226.

DAZZI, Camila; VALLE, Arthur (org.). Relatório do Diretor da Escola Nacional de Belas Artes Rodolpho Bernardelli ao Ministério da Instrução Pública, Correios e Telegráfos, em maio de 1891. 19\&20, Rio de Janeiro, v. V, n. 3, jul. 2010. Disponível em: http://www.dezenovevinte.net/documentos

DIAS, Belidson et. al. Looking at new trends and policies in Latin American Art Education. In: BARTON, Giorgina; BAGULEY, Margaret (ed.). The Palgrave Handbook of Global Arts Education. London: Palgrave Macmillan, 2017.

DIAS, Belidson. O/I mundo da educação da cultura visual. Brasília: PPG-Arte/UnB, 2011.

DIAS, Belidson; IRWIN, Rita (org.). A/r/tografia. Santa Maria: Editora da UFSM, 2013.

DUARTE, Marisa. A educação pela arte: O caso garagem. Brasília: Editora UnB, 2011.

EFLAND, Arthur. A History of Art Education: Intellectual and Social Currents in Teaching the Visual Arts. New York: Teachers College Press, 1990.

FÁVERO, M. L. A. Anísio Teixeira e a Universidade do Distrito Federal. Revista Brasileira de História da Educação, v. 17, 2008, p. 161-180.

FRANGE, L. B. Arte no processo educativo. Educação, v. 31, 2006, p. 213-226.

HALL, James. Making art, teaching art, learning Art: exploring the concept of the artist teacher. International Journal of Art \& Design Education, v. 29, 2010, p. 103-110.

HEBERT, Read. A educação pela arte. São Paulo: Martins Fontes, 2001.

HELGUERA, Pablo. Education for Socially Engaged Art: a Materials and Tecniques Handbook. New York: Jorge Pinto Books, 2011.

HIGGINS, Hannah. Fluxus Experience. California: University of California Press, 2002.

HODGINS, Wayne. The Future of Learning Objects. In: WILEY David (Ed). The instructional use of Learning Objects. 2000. Disponível em: http://reusability.org/read/. Acesso em: 20 dez. 2016.

HONORATO, Cayo. A formação do artista-educador, aproximadamente. In: CHAUD, E. Anais: VII Seminário Nacional de Pesquisa em Arte e Cultura Visual. Goiânia: UFG, FAV, 2014, p. 522-532.

HOWKINS, J. Economia Criativa: como ganhar dinheiro com ideias criativas. Trad. Griesi Ariovaldo. Brasil: M. Books, 2012.

HUNTER-DOGINER, Tracey. Contextual A.R.T. factors in the evaluation of visual art educators. Art Education Policy Review, n. 114, 2013, p. 170-177.

KALIN, Nadine. (de)Fending Art Education Through the Pedagogical Turn. The Journal of Social Theory in Art Education. v. 32, p. 42-55, 2012.

KALIN, Nadine. The Neoliberarization of Creativity Education. Democratizing, Destructing and Decreating. Palgrave Macmillan, 2018. 
KUONI, Carin (org.). Energy Plan for the Western man: Joseph Beuys in America. New York: Four Walls Eight Windows, 1993.

MACHADO, Rosilene; FLORES, Cláudia. Quando fui professor de desenho. Reflexões sobre uma formação. Educação Matemática em Pesquisa, São Paulo, v. 15, n. 2, 2013, p. 431-446.

MADOFF, Steven. Art School: Propositions for the 21st Century. London: The MIT Press, 2009.

MINISTÉRIO DA EDUCAÇÃO. Diretrizes Curriculares Nacionais para o Curso de Graduação em Artes Visuais - Resolução CNE/CP no 1/2009. 2009. Brasília: MEC/CNE/CEB. Disponível em: http://portal.mec.gov.br/cne/arquivos/pdf/2009/rces001_09.pdf.

MINISTÉRIO DE NEGÓCIOS DO IMPÉRIO. (1855). Decreto $n$. 1603, 14 de maio de 1855. Disponível em: http://www.dezenovevinte.net/documentos/documentos.htm.

NOTES FOR AN ART SCHOOL. Manifesta 6. Nicosia, Cyprus. 2006. Disponível em: http://manifesta.org/manifesta-6/. Acesso em: 9 jun. 2013.

O'NIELL, Paul; WILSON, Mick (ed.) Curating and the educational turn. London: Open Editions, 2010.

PAIM, Antônio. A busca de um modelo universitário. In: SCHWARTZMAN, S. (org.). Universidade e Instituições Científicas no Rio de Janeiro. Brasília: CNPq, 1982.

PODESVA, L. K. A Pedagogical Turn: Brief Notes on Education as Art. Fillip, 6 Projectile Publishing Society, Vancouver, British Columbia Summer 2007. Disponível em: http://fillip.ca/content/apedagogical-turn. Acesso em: 12 mar. 20012.

ROGOFF, Irit. Studying visual culture. In: MIRZOEFF, Nicholas (ed.) The visual culture reader. 2. ed. London: Routledge, 1998.

SCHWARTZMAN, Simon. Gustavo Capanema e a educação brasileira: uma interpretação. Revista Brasileira de Estudos Pedagógicos, v. 66, n. 13, maio/ago, 1985, p. 165-172.

SILVA, L.; AZEVEDO, M. reforma educativa a partir dos anos 1990: implementação na América Latina e Caribe, e particularidades brasileiras. Holos, ano 28, v. 2, p. 250 -260, 2012.

SQUEFF, L. C. A Reforma Pedreira na Academia de Belas Artes (1854-1857) e a constituição do espaço social do artista. Cadernos Cedes, v. 51, 2000, p. 103-118.

STANKIEWICZ, Mary Ann. Constructing an International History of Art Education: Periods, Patterns and Principles. The International Journal of Arts Education, v. 7, n. 1, 2009, p. 1-20.

SULLIVAN, Graeme. Art Practice as Research: Inquiry in Visual Arts. Los Angeles: SAGE Publications, 2010.

SULLIVAN, Graeme. Artistic thinking as transcognitive practice: a reconciliation of the process-product dichotomy. Visual Arts Research, v. 22, n. 1, p. 2-17, 2002.

UNIVERSIDAD NACIONAL DE COLOMBIA. Luis Camnitzer: la ensenanza del arte como fraude. Conferencia 21 de marzo de 2012. Vimeo 1:14:23. Disponível em: https://vimeo.com/41144656. Acesso em: abr. 2019.

WICK, Rainer. Pedagogia da Bauhaus. São Paulo: Martins Fontes, 1989. 